\title{
Developing an Integrated Conceptual Framework of Pro-Environmental Behavior in the Workplace through Synthesis of the Current Literature
}

\author{
Faye V. McDonald
}

Portsmouth Business School, Portsmouth University, University House, Winston Churchill Avenue, Portsmouth PO1 2UP, UK; E-Mails: fayemcd@gmail.com; eco90455@myport.ac.uk;

Tel.: +44-2392-477-563

Received: 20 April 2014; in revised form: 15 July 2014 / Accepted: 23 July 2014/

Published: 4 August 2014

\begin{abstract}
Recent studies have begun to bridge the gap between general and workplace pro-environmental behavior by adapting specific existing behavioral models to the workplace environment. This conceptual article proposes a different approach by synthesizing the current general and workplace literature to develop a new model of the antecedents to pro-environmental behavior. Guided by this approach, this paper combines the insights of the current general and workplace models to develop an integrated framework of pro-environmental behavior in the workplace. In doing so, an overview of the current general and workplace literatures will be provided as well as their similarities and differences highlighted. The proposed framework will provide further insights into the antecedents of workplace pro-environmental behavior and identify common findings across the different existing workplace models. This theory can be the basis for further research in order to provide a comprehensive picture of the antecedents of pro-environmental behavior in the workplace. Lastly, implications for specific interventions to develop targeted Human Resource Management practices and work towards achieving environmental sustainability will be discussed.
\end{abstract}

Keywords: pro-environmental behavior; environmental concern; values; attitudes; habit; Theory of Planned Behavior; human resource management; sustainable behavior; organizational behavior; environmental psychology 


\section{Introduction}

The climate is changing. With global warming on the increase and species and their habitats on the decrease, chances for ecosystems to adapt naturally are diminishing thus causing many to agree that climate change is one of the greatest threats facing the planet. Much of this environmental degradation is caused by human behavior, as the Intergovernmental Panel of Climate Change (IPCC) just recently reconfirmed [1]. The IPCC defines climate change as a statistically significant variation in either the mean state of the climate or in its variability, persisting for an extended period (typically decades or longer) caused by internal processes, external forces, or persistent anthropogenic changes [2]. While internal causes are natural causes such as the continental drift changing the flow of ocean currents, external causes include radiation from the universe, eruptions on the sun or the changes in the earth's orbit [2,3]. The important statement, however, is that anthropogenic (human) behavior plays a significant role in climate change.

With this in mind, the pivotal role organizations and their employees play in tackling climate change has been acknowledged by governments, communities and scholars. One approach to reduce the impact of organizations on the environment is by understanding employee's pro-environmental behaviors (PEB), such as recycling, waste management, reduction in energy consumption or any other behavior that consciously seeks to minimize the negative impact of one's actions on the environment [4]. However, the question "how can pro-environmental behavior in the workplace be achieved" has just recently been explored [5]. The research aiming to answer this question generally examines two domains: Organizational and individual determinants [6,7]. Research looking at the organizational level explicitly refers to the context and its effect on employee's behavior and includes variables such as organizational culture, structure and environmental policies etc. Individual determinants bear a direct relationship to the individuals and their behavior within the organization and include variables such as attitudes, intentions etc. [6].

It has been acknowledged that these categories are interrelated suggesting that both dimensions have to be considered in order to understand pro-environmental behavior in the workplace [7]. Advances have been made to bridge the gap between these two domains, with workplace models emerging, such as the Voluntary Pro-environmental Behavior of Employees (VPBE) model by Lülfs and Hahn or Tudor's conceptual model [5,7]. However, the existing models are based only on a limited field of research, as they modify and extend particular behavioral models and underestimate aspects investigated by others. Therefore, a different approach to develop an integrated framework of pro-environmental behavior in the workplace based on general and workplace models is suggested: synthesizing the existing general and workplace literature. This approach will enable to compare the range of current theories and models on a like for like basis and will integrate the insights into one conceptual framework. Furthermore, it will provide an integrated model of pro-environmental behavior in the workplace, which can be the basis for further research and discussion, as well as help develop targeted Human Resource Management practices and work towards achieving environmental sustainability.

The present paper is structured as follows: Section 2 will review the current literature on general and workplace pro-environmental behavior, followed by the methodology in Section 3. Sections 4 and 
5 will present the data gathering and analysis process before closing with results, discussions and conclusions in Sections 6 and 7.

\section{Current State of Knowledge}

This section will briefly introduce the current state of knowledge of general pro-environmental as well as workplace pro-environmental behavior. The aim of this section is to provide an initial overview to establish the need for an integrated framework of pro-environmental behavior in the workplace. This section will be structured by presenting models on general pro-environmental behavior in Section 2.1 and workplace models in Section 2.2. The general pro-environmental theories will be structured by their main factors examined: intrapersonal, motivational and interpersonal factors.

\subsection{General Pro-Environmental Behavior Literature}

\subsubsection{Intrapersonal Factors}

Most literature looking at internal factors and their influence on PEB originate from the field of Social Psychology and can be broadly categorized into three theoretical domains: moral, rational choice and non-rational choice [8,9]. Moral Theories focus on environmental values as the main driver of PEB whilst Rational Choice Theories focus on the impact of attitudes. The theories in the last category "non-rational choice" integrated non-rational factors such as habit and affect to the existing rational models in order to provide more comprehensive frameworks for pro-environmental behavior.

"Moral Theories" focus on environmental values as the main driver of PEB [8-15] Supporters of this approach such as Schwartz, Stern and Steg assume that altruistic or moral reasons are the cause of pro-environmental behavior. The New Environmental Paradigm (NEP) [16,17] and the Norm Activation Theory (NAT) [18-20] are amongst the leading constructs in this field. The New Environmental Paradigm argues that environmental concern is the key to pro-environmental behavior, whilst the Norm Activation Theory contends that personal norms (created by awareness of consequences and ascription of responsibility) antecede environmentally friendly behavior. These were later integrated into the Value-Belief-Norm Theory (VBN) [21], which is now considered to be a comprehensive and widely accepted moral theory for PEB amongst Moral Theory Psychologists.

VBN indicated a strong initial support for the NAT theory's contention that personal moral norms are the main basis for an individual's general predispositions to environmental behavior. However, the theory was extended claiming that not just altruistic but biospheric (i.e., focus on the welfare of the environment and biosphere) and egoistic beliefs in conjunction with our ecological worldview (NEP) were the basis for our behavior. If they were activated by our beliefs about our responsibility and the consequences of our actions our norms would be activated, which in addition would affect our behavior [12,21,22].

Another social psychologist theory used to explain pro-environmental behavior is the Theory of Planned Behavior (TPB). In contrast to the emphasis the previous theories gave moral considerations, the Theory of Planned Behavior adopts a rational decision-making framework [9]. The premise of this rational choice model is that human behavior is a continual process of making deliberate choices between distinct courses of action. Faced with such choices, we weigh up expected benefits and costs 
of the different actions and choose the one that offers the highest expected net benefit or lowest expected net cost [8]. A central concept of the theory is that a person's behavior is dependent on the attitude of the behavior, which is influenced by its beliefs and evaluations of it. This attitude can then lead to an intention to act. If this intention is high and the person is able to act on it, then it will demonstrate this behavior [23,24]. However, the authors recognized that attitudes alone do not predict behavior alone. They also discuss that subjective norms, i.e., how people would view them if they performed that behavior, can influence the person in the specific situation. The more favorable the individual's norms are, the stronger the behavioral intention [9]. Furthermore, Ajzen and Fishbein emphasized that perceived behavioral control can also impact acting on our attitudes. Therefore, the person must not just be able to act on its intention but must perceive that it is possible to act, thus implying that the person must perceive it being easy to behave as intended [23].

At the heart of this rational choice theory lays the image of calculated decision making. However, this conception of human action has been subject to increasingly assault in the last half of the century, with scholars arguing that non-rational components, such as habits and emotions have to be considered to explain pro-environmental behavior. Two theories that extended Ajzen and Fishbein's model to cover non-rational dimensions such as emotions and habits are the Theory of Interpersonal Behavior and the Comprehensive Action Determination Model.

Triandis' Theory of Interpersonal Behavior (TIP) (1979) extended TPB to cover emotive as well as habitual dimensions, recognizing that human behavior is not always rational. More specifically, Triandis proposed that behavior is determined by four dimensions: Intention, affect, habit and facilitating conditions. Intention refers to the individual's motivation regarding the performance of the behavior and can be influenced by the individual's attitudes, emotions or norms (social factors). Triandis is one of the few theorists to offer an explicit role of affective factors on behavioral intentions. Norms appear to be conceptualized as social rules about what should and should not be done [8]. Facilitating conditions represent objective factors that can make the behavior easier or harder to do. Habit constitutes the level of routinized behavior [25]. It is important to stress that Triandis argued that behavior in any situation is a function partly of the intention, partly of the habitual responses, and partly of the situational constraints and conditions. The intention is influenced by social and affective factors as well as by rational deliberations. One is neither fully deliberative, in Triandis' model, nor fully automatic [26].

The Comprehensive Action Determination Model (CADM) integrated TPB and NAT and added the non-rational component habit to address the multidimensionality of human behavior. The CADM argued that environmental behavior is an outcome of the complex interrelationship among normative, intentional, habitual, and situational processes [27]. The core assumption of CADM is that behavior is directly predicted by intention, perceived behavioral control, and habit. Following the TPB, an intention refers to the feeling of being ready and willing to perform a behavior, whereas perceived behavioral control corresponds to a perceived ability to perform the behavior. Habit refers to both behavioral routines and behavioral automaticity. On the second level, in line with the TPB, intentional process is generated from attitude toward the behavior, perceived behavioral control, and social norms. Attitude regards person's evaluation on the behavior, whereas social norms indicate the influence of relevant other people on the behavior (such as peer pressure). In addition, personal norms, which reflect to the feeling of moral obligation according to person's values, also influence intention directly. 
Normative processes (i.e., social norms, personal norms) do not influence behavior directly, but are mediated by intentional and habitual processes. Personal norms, themselves, are considered stable, yet perceived behavioral control could impact personal norms in the long terms (i.e., situational influences deactivate personal norms if behavior, which is in line with norms, is not easy to do) [28].

\subsubsection{Motivational Factors}

Besides internal factors such as attitudes, values and emotions, motivation can act as a force to initiate behavior. This section will introduce the motivational theories that have been applied to explain general pro-environmental behavior: Protection motivation theories as well as intrinsic and extrinsic motivation.

Protection Motivation Theory (PMT) was originally proposed to provide conceptual clarity to the understanding of fear appeals and was later applied to explain pro-environmental behavior [29,30]. In particular, the Theory of Protection Motivation states that that we protect ourselves based on four factors: the perceived severity of a threatening event, the perceived probability of the occurrence, or vulnerability, the efficacy of the recommended preventive behavior, and the perceived self-efficacy [31,32]. Protection motivation is the result of the threat appraisal and the coping appraisal. Threat appraisal is the estimation of the chance of contracting a disease (vulnerability) and estimates of the seriousness of a disease (severity). Coping appraisal consists of response efficacy and self-efficacy. Response efficacy is the individual's expectancy that carrying out recommendations can remove the threat. Self-efficacy is the belief in one's ability to execute the recommend courses of action successfully. The theory was applied to explain pro-environmental behavior and it was concluded that one's attitudes toward the prevention of climate change, perceived severity of climate change, response efficacy, and self-efficacy regarding climate change prevention are predictors of one's intentions to engage in a series of pro-environmental behaviors [33].

A similar model analyzing the relationship between coping and behavior is Lazarus and Folkman's Cognitive Theory of Stress, which was also applied to explain pro-environmental behavior [34]. Lazarus and Folkman [34] proposed that there are many ways of coping with stress. Their effectiveness depends on the type of stressor, the particular individual, and the circumstances. They further suggested there are two types of coping responses, emotion focused and problem focused: Emotion-focused coping involves trying to reduce the negative emotional responses associated with stress such as embarrassment, fear, anxiety, depression, excitement and frustration. This may be the only realistic option when the source of stress is outside the person's control. Emotion-focused strategies are often less effective than using problem-focused methods. Homburg [32] applied the theory in order to explain pro-environmental behavior and demonstrated that environmental stress factors such as anthropogenic, environmental problems including climate change, environmental pollution or accidents and disasters, as well as any physical and social environmental conditions that the average person would perceive as actually or potentially threatening, damaging, harmful or depriving could trigger a coping response in individuals. Therefore, he concluded that perceiving environmental stressor as a threat in conjunction with self-efficacy could explain pro-environmental behavior [32]. 
Another field of motivational research examined the influence of intrinsic as well as extrinsic motivation on pro-environmental behavior. Self-determination theorists such as Ryan and Deci [35,36] support the argument that internal motivation can explain pro-environmental behavior. They suggested that intrinsic and extrinsic motivation can be arranged on an internal-external continuum according to the individual's perception of relative autonomy. Motivations that involve a higher perception of autonomy are more internal and represent a higher quality of engagement. Internalization is likely to occur only if the three psychological needs competence, relatedness, and autonomy are satisfied. They and their supporters such as Pelletier further argued that self-determined forms of motivation were associated with more positive responses on various environmental behaviors and that internalized motivation predicted environmentally responsible behavior [37-39]. Extrinsic motivation on the other hand refers to behavior that is driven by external rewards such as money, fame, grades, and praise. This type of motivation arises from outside the individual, as opposed to intrinsic motivation. Theories such as Incentive Theory by Killeen and the Expectancy Value Theory by Vroom have argued that external motivators can impact on human behavior [40]. Applied to pro-environmental behavior various studies have shown that extrinsic motivation can be an antecedent to PEB. Bedford and colleagues [41] demonstrated that more complex environmental behaviors were only undertaken if the price incentive was right, whilst Kassirer [42] concluded that incentives are powerful tools for encouraging and discouraging behaviors. Incentives also play a role in community based social marketing. Doug McKenzie-Mohr [43,44] argued that financial incentives can provide the motivation for individuals to perform an activity that they already engage in more effectively or to begin an activity that they otherwise would not perform.

\subsubsection{Environmental Education}

Another common explanation for engagement in environmental behavior is awareness. Environmental educationalists claim that individuals who are not aware of the detrimental effects their actions are having on the environment or what they can do to positively alert their behavior, are simply not engaged in pro-environmental activities. The solution is often seen to lie in the provision of information and knowledge dissemination through learning and education, as it is inferred that if individuals were aware of the issues and how they can contribute in solving them, they would alter their behavior accordingly [43-45]. Scholars in the field of Environmental Education have as early as 1986 provided statistical evidence to support the claim that awareness and knowledge is a predictor of pro-environmental behavior and awareness campaigns were developed to educate the general public [46,47]. However, even though environmental knowledge is in fact able to predict behavior in certain situations, at the same time, campaigns in the mass media that provide environmental information have brought disappointing results [46,48-53]. Following from this, a current trend within the subject area seeks to move from an approach of ideology and activism to one that allows making informed decisions and taking action based on experience as well as data called the Action Competence Approach [49,54,55]. In a broad sense this approach argues that people need the knowledge as well as have the ability and willingness to take action on issues that interest them [56]. If these conditions are met, environmentally friendly action will occur. 


\subsubsection{Psychosocial Determinants}

Scholars from another field of research, such as Schultz, Zeleny, Gatersleben, Stek and Vlek [57,58] have proposed that demographic factors play a significant role in environmental behavior. Since the 1970s, a vast amount of studies were conducted accumulating statistical data about the population and their correlation to environmental behavior [57]. While some studies focused on identifying a relationship between demographic variables and specific behaviors, such as recycling, bus use or the purchase of a green product, others concentrated on determining a relationship to environmental behavior in general. Demographics variables such as level of education, gender, age, income, as well as place of residence have all shown to have significant correlations to pro-environmental behavior [59].

\subsubsection{Interpersonal Factors}

The last field of research, discussed in this section, examines the effect of interpersonal factors on pro-environmental behavior including Structuration Theory, Focus Theory of Normative Conduct and Self Identity Theory.

Giddens' Theory of Structuration [60,61] outlines the social processes involved in the evolution of aspects of society by arguing that social life is more than random individual acts, but is not merely determined by social forces [62]. Giddens suggests, human agency and social structure are in a relationship with each other, and it is the repetition of the acts of individual agents which reproduces the structure. This means that there is a social structure - traditions, institutions, moral codes, and established ways of doing things; but it also means that these can be changed when people start to ignore them, replace them, or reproduce them differently. Hobson [50,63] applied Giddens' theory to present a theoretical framework that explained the low uptake of public messages that link environmental issues with individual behavior. Looking at case studies of government organizations that aim to change the public's environmental behavior, she concluded that instead of messages concentrating on more and better science, communication that forms connections between the forms of knowledge that links to everyday and experiential environments are needed. She argued that individuals should not be seen as passive respondents to institutional interpretations of environmental problems. Instead they should be seen as curious actors who wish to debate the nature of environmental problems [64].

A theory specifically looking at the influence of social norms on pro-environmental behavior is the Focus Theory of Normative Conduct (FTNC) [65], which argues that there are two kinds of norms: descriptive and normative. Descriptive norms carry little moral weight and simply refer to the perception we hold about normal behavior in any given situation. These norms play an adaptive role in our society. By copying these behaviors people are able to bypass the mental effort involved in thinking and to free up cognitive resources. In contrast to descriptive norms, Cialdini refers to injunctive norms. This kind of norm reflects moral rules and guidelines. They tend to motivate and constrain our actions. Social norms therefore operate in two ways: they provide examples of how we should behave and provide guidance. Cialdini conducted experiments to confirm how norms influence pro-environmental behavior. In one investigation [66], participants were given the opportunity to litter 
into either a previously clean or littered environment after first witnessing a confederate who either dropped trash or simply walked through. By varying the state of environment, the descriptive norm was manipulated. By manipulating whether the confederate dropped the litter the salience of the descriptive norms was manipulated. The experiment showed that there was more littering in the littered environment than in the clean environment. In addition, the most littering occurred when participants saw a model drop trash into a littered environment $[65,67]$.

Social identity is a person's sense of who they are based on their group membership(s). Tajfel [68] proposed that the groups (e.g., social class, family, football team etc.) which people belonged to were an important source of pride and self-esteem. Groups give a sense of social identity: a sense of belonging to the social world. In order to increase self-image people enhance the status of the group to which they belong. They can also increase their self-image by discriminating and holding prejudice views against the out group (the group they don't belong to). This is known as in-group (us) and out-group (them). Social identity theory states that the in-group will discriminate against the out-group to enhance their self-image. The concept of self-identity as an antecedent of behavior has been applied to pro-environmental behavior as well. A literature review by Conner and Armitage [69] concluded that self-identity independently predicted intention whilst other studies showed that self-identity was a significant predictor for certain pro-environmental behaviors [52,70].

As the brief overview shows, various fields of research have explained general pro-environmental behavior and differ in their assumptions, methodologies and approaches. For example, some theories were specifically designed to address environmental behavior such as the Comprehensive Action Determination Model or the Value-Belief-Norm Theory. Other theories have been used to explain various human behaviors but have also been successful in explaining PEB such as the Theory of Planned Behavior. All have shown validity and explanatory value for pro-environmental behavior within their respective domains. Some of these theories are contradictory in their basic assumption of human behavior; however, in many cases they complement each other, as Triandis' addition of non-rational factors to enhance the rational Theory of Planned Behavior for example shows.

\subsection{Workplace Pro-Environmental Behavior Literature}

This section will introduce the literature that extended existing models and applied them to the workplace setting in order to explain employee pro-environmental behavior. Similarities and differences between them and the previously mentioned general pro-environmental theories as well as their limitations will briefly be discussed and the need for a theory that integrates the learnings of all fields of research will be highlighted.

Based on the Norm-Activation Model, the Theory of Planned Behavior and the Comprehensive Action Determination Model previously discussed, Lülfs and Hahn [5] developed the Voluntary Pro-environmental Behavior of Employees (VPBE) model in order to explain pro-environmental behavior in the workplace. Their model suggests that organizational context and individual determinants, perceived behavioral control, personal norms, attitudes, intentions and habits are the key predictors of pro-environmental behavior in the workplace [5]. The VPBE model bridges the gap between workplace and general pro-environmental behavior models by integrating three general proenvironmental behavior models and extending them to the workplace environment by adding the 
organizational dimension. However, even though the model acknowledges the interaction between individual and organizational determinants it emphasizes the intrapersonal dimension (perceived behavioral control, personal norms, attitudes, intentions and habits) over the organizational dimension (organizational context). Furthermore, it neglects the learnings from other comprehensive theories such as Theory of Interpersonal Behavior (i.e., affect) and other fields of environmental research such as Environmental Education (i.e., awareness). Additionally, the model includes the Comprehensive Action Determination Model, which integrated the learnings form previous models such as the Norm Activation Theory and Theory of Planned Behavior but neglected that the Norm Activation Theory has higher explanatory power if integrated into the Value-Belief-Norm Theory.

Using a similar approach but only extending one theory to the workplace environment, Lo and her colleagues [71] explained energy saving behaviors in the workplace with an extended TPB, by adding perceived habit and organizational context. Their findings suggest that organizational context had an influence on office energy saving behaviors and that perceived norms and perceived control also played a role [71]. Further qualitative studies confirmed the conjecture that individual and organizational variables influence employee's pro-environmental behavior. [72-74]. Ramus and Killmer also used the Theory of Planned Behavior as the basis for their framework for prosocial behavior in the workplace. Personal predisposition, supervisory support, self-efficacy and organizational norms were the key predictors for their framework [27,75]. Whilst both theories acknowledge the individual and organizational dimensions, as Lülfs and Hahn's model did and considered the rational and non-rational dichotomy of human behavior, they do not include the learnings from the moral theories, psychosocial determinants, environmental education or motivational theories discussed earlier. The Theory of Reasoned Action was also employed to predict levels of paper recycling and to identify the socio-psychological factors which influence performance of this action by. The faculty of a medium-sized northwestern public university where recycling opportunities are institutionally supported and convenient served as the survey population. The results lend strong support overall to the theory and demonstrated its utility for predicting and understanding individual actions such as source separation-recycling which could reduce environmental pollution and natural resource depletion [76]. Scherbaum and his colleagues [77] on the other hand chose the Value-Belief-Norm theory as the basis for their workplace model and argued that environmental concern and personal norms are the predictors of workplace pro-environmental behavior. In contrast to the previous models, the moral perspective of pro-environmental behavior is highlighted with this approach but ignores the learnings from rational theories and more integrated theories to include variables such as attitudes, awareness or habit. Furthermore, motivational determinants are not included in the framework as well as workplace determinants such as organizational context.

Tudor and his colleagues [7] proposed a conceptual framework recognizing the individual and organizational dimension as the previous studies did but with a greater focus on the organizational influence on pro-environmental behavior. Factors such as culture, context, department size, policies are all considered key predictors in this model. Compared to the previous models, the set of interpersonal factors group dynamics and management support are also more specific to the workplace environment. However, it overlooks other social factors originating from the general behavior literature such as social identity, or social norms and individual variables such as attitudes, motivation age and beliefs are only mediating variables to the organizational determinants [7]. Further learnings from more 
integrated theories such as TIP and CADM to include non-rational variables such as habit and affect are also not recognized. William Young and his colleagues reviewed Tudor's model and concluded that several additional factors were not present in the framework, such as financial incentives and environmental infrastructure and revised the model by enhancing the importance of individual determinants by giving it a direct influence on employee behavior [6]. However, the non-rational and social dimension from the general behavior literature was still not acknowledged. Coming from a similar perspective by focusing on the organizational dimension of workplace pro-environmental behavior, Daily and her colleagues proposed a framework concentrating on variables such as corporate social performance, supervisory support, concern and commitment to the organization, which was later reduced to the variables environmental concern, organizational commitment and perceived organizational support by Temminck and her colleagues [78,79]. As with the previous models, the learnings from general behavior models to add specific intrapersonal variables such as attitudes, habit and affect is not considered.

Lastly, some of the theories previously discussed, the Theory of Interpersonal Behavior, Structuration Theory, Competence Action Determination Model, Cognitive Theory of Stress have been directly applied to explain workplace behavior $[32,64,80]$. Though all showed some explanatory power towards pro-environmental behavior it is clear how they did not reflect on the learnings form other general and workplace models.

This brief overview of the workplace pro-environmental behavior literature demonstrates that advances have been made to understand employee pro-environmental behavior. Extending existing behavioral models to the workplace environment resulted in the addition of the organizational context as well as in the emphasis of interpersonal factors through the addition of group dynamics and management support. However, this review also shows the limitations of this approach. Focusing on one theory or an area of study ignores the findings of other areas so that the full picture of workplace pro-environmental behavior has so far not been fully documented. However, similarities can be found between all the theories discussed in this paper, suggesting that a synthesis is possible. The notion that attitudes are key, as well as intention and values is supported across various theories and the addition of habit, identity and facilitating conditions is also a common theme. Social norms and the social environment also play an important role in general as well as workplace models. Therefore, it is suggested that combining the insights of the current general and workplace models can be useful to provide further knowledge into possible antecedents of workplace pro-environmental behavior by developing a theory based on their findings. In order to do that, it was decided to use synthesise the current general and workplace pro-environmental literature, which will be discussed in the next section.

\section{Methodology}

Building upon the gaps and similarities highlighted in the previous section the current section will create a new framework from both literature sources (general and workplace).

The stages of data gathering are as follows and closely resemble a systematic review of the current body of literature [81,82]:

(a) Define: To define the inclusion and exclusion criteria for the literature search, identify the fields of research, appropriate sources as well as decide on the specific search terms 
(b) Search: Document searches and search terms, what the sources were, and their results

(c) Select: The sample of texts are selected

The data analysis was done in three stages. The features and uses of these methods are explained below.

(a) 1st stage: The process of selecting and naming categories from the analysis of the data. It is the initial stage in data acquisition and relates to describing overall features of the phenomenon under study. Variables involved in the phenomenon are identified and labelled.

(b) 2nd stage: The data is put together in new ways. This is achieved by seeking to identify causal relationships between categories. The aim is to make explicit connections between categories and sub-categories. This process is often referred to as the "paradigm model" and involves explaining and understanding relationships between categories in order to understand the phenomenon to which they relate.

(c) 3rd stage: The last stage involves the process of selecting and identifying the core category and systematically relating it to other categories. It involves validating those relationships, filling in, and refining and developing those categories.

The data gathering process will be explained in Section 4 whilst the data analysis process will be explained in Section 5 .

\section{Data Gathering}

In order to be included the coding process, sources had to meet the following inclusion criteria:

(a) Created to explain pro-environmental behavior and various studies have shown a good fit

(b) A general behavioral theory or model but has been applied to general pro-environmental behavior and various studies shown it had a good fit

(c) A general behavior theory or model but has been applied to general pro-environmental behavior with few studies but shown a better fit than established theories

(d) If the concept, theory was integrated into/linked to a better fit model for pro-environmental behavior

(e) Workplace pro-environmental behavior theories/ models

Exclusion criteria:

(a) Has been tested since 1980. (Organizational settings change, so old research findings would have less validity [83].

(b) General behavioral models that do not examine pro-environmental behavior as defined as behavior that consciously seeks to minimize the negative impact of one's actions on the environment

(c) Workplace models that only examined the antecedents of manager behavior

(d) Workplace models examining overall organizational behavior and not looking at individual employee behavior 
The data was gathered from the literature in the previous chapters: pro-environmental behavior in general and in the workplace. Data from multiple sources provides different perspectives and the usage of different sources of information increases the validity of the model by bringing together evidence from different disciplines, including social psychology, organizational behavior, professional research, education, environmental psychology and business management [84,85]. Research conducted within a broad range of industries, such as universities, health organizations and manufacturers in different companies were included to ensure generalizability.

The search was not meant to be an exhaustive literature review, collecting every study conducted but to gather enough evidence that the model met the above criteria. The search found a total of 114 bodies of literature explaining general or workplace pro-environmental behavior, 25 of which met the above criteria, as Table 1 below shows:

Table 1. Sources met the above criteria.

\begin{tabular}{lc}
\hline Source & Met Criteria \\
\hline New Environmental Paradigm & $\mathrm{A} / \mathrm{D}$ \\
Norm-Activation Theory & $\mathrm{A}$ \\
Value-Belief-Norm Theory & $\mathrm{A}$ \\
Theory of Planned Behavior & $\mathrm{B}$ \\
Competence Action Approach & $\mathrm{A}$ \\
Theory of Interpersonal Behavior & $\mathrm{C}$ \\
Comprehensive Action Determination Model & $\mathrm{A}$ \\
Protection Motivation Theory & $\mathrm{D}$ \\
Cognitive Theory of Stress & $\mathrm{D}$ \\
Self-Determination Theory & $\mathrm{C} / \mathrm{D}$ \\
Structuration Theory & $\mathrm{D}$ \\
Social Identity Theory & $\mathrm{D}$ \\
Focus Theory of Normative Conduct & $\mathrm{A}$ \\
Environmental education & $\mathrm{A}$ \\
Action Competence Approach & $\mathrm{A}$ \\
Psychosocial Demographics & $\mathrm{A}$ \\
Tudor's Conceptual Framework & $\mathrm{E}$ \\
Young's Process Framework & $\mathrm{E}$ \\
Voluntary Pro-environmental Behavior of Employees & $\mathrm{E}$ \\
Lo's extended Theory of Planned Behavior & $\mathrm{E}$ \\
Ramus and Killmer's model & $\mathrm{E}$ \\
Temminck and colleagues' model & $\mathrm{E}$ \\
Scherbaum and colleagues' model & $\mathrm{E}$ \\
Jones's model & $\mathrm{E}$ \\
Daily and colleagues' model & $\mathrm{E}$ \\
\hline
\end{tabular}

\section{Data Analysis}

The data was analyzed systematically through three stages mentioned in Chapter 3. Open coding was the first stage, which generated a lot of open codes for the data. Then these open codes were interpreted and categorized into higher concepts until the core categories emerged. Axial coding 
was the second stage, which tried to establish the relationship between the core categories and sub-categories. Selective coding was the final stage of coding, which aimed to integrate and saturate the emerging theory. All three states will be discussed in the following sections.

\subsection{1st Stage}

The first stage began with reading through the articles explaining pro-environmental behavior and highlighting the passages where the methodology, variables and results were discussed. Particular interest was given to any statistical analysis such as multiple regression and correlations between variables and pro-environmental behavior. Next, the articles were re-read for the purpose of generating open codes as highlighted in Table 2. The focus was on specific variables such as values, attitudes etc. Variables were included that showed a moderate to strong statistically significant correlation to proenvironmental behavior or showed some explanatory power in multiple regression analysis in several studies conducted by different researchers. If the study was specifically applied to the workplace, the variables were automatically included as there aren't many studies looking at workplace behavior. As the coding went on, each variable was compared with the previous variables and codes for differences and similarities. Any codes that were the same or similar, were coded identically. If they were different, a distinct label was used. Besides the name and the type of the code, the article was recorded for future analysis, tracing and retrieving of data.

This phase of the research identified that some of the variables used in the literature were defined differently. For example personal norms, which in the Norm Activation Theory was originally defined as awareness of consequences and ascription of responsibility, was later defined as awareness of consequences, ascription of responsibility and social norms in the Comprehensive Action Determination Model [86]. Furthermore, studies have shown that the variable environmental concern measures the same as awareness of consequences, but this was not considered by other theories [87]. The term beliefs was considered a moderating variable for attitudes in the Theory of Planned Behavior and Interpersonal Behavior but in other theories such as Value-Belief-Norm Theory it was defined as the combination of environmental concern, awareness of consequences and ascription of responsibility. It was decided to use the definition that was supported by the most empirical evidence though the term beliefs was not included in the coding due to too many inconsistencies in the definition.

After the first phase the following variables were identified:

Table 2. Variables identified after 1st stage.

\begin{tabular}{ll}
\hline 1st Stage & Source \\
\hline $\begin{array}{l}\text { Environmental concern (defined as altruistic, } \\
\text { biospheric values and awareness of }\end{array}$ & $\begin{array}{l}\text { New Environmental Paradigm, Value-Belief-Norm } \\
\text { Theory, Protection Motivation Theory, Temminck and } \\
\text { consequences/needs/threat) }\end{array}$ \\
\hline & $\begin{array}{l}\text { Daily and colleagues' model } \\
\text { Awareness of responsibility }\end{array}$ \\
& $\begin{array}{l}\text { Norm-Activation Theory, Value-Belief-Norm Theory, } \\
\text { Comprehensive Action Determination Model, Voluntary } \\
\text { Pro-environmental Behavior of Employees }\end{array}$ \\
\hline
\end{tabular}


Table 2. Cont.

\begin{tabular}{|c|c|}
\hline 1st Stage: & Source: \\
\hline Personal Norms (defined as AC/NEP $+\mathrm{AR}$ ) & $\begin{array}{l}\text { Norm-Activation Theory, Value-Belief-Norm Theory, } \\
\text { Comprehensive Action Determination Model, Voluntary } \\
\text { Pro-environmental Behavior of Employees, extended } \\
\text { Theory of Planned Behavior, Ramus and Killmer's } \\
\text { model, Scherbaum and colleagues' model }\end{array}$ \\
\hline Intention & $\begin{array}{l}\text { Theory of Planned Behavior, Theory of Interpersonal } \\
\text { Behavior, Comprehensive Action Determination Model, } \\
\text { Voluntary Pro-environmental Behavior of Employees, } \\
\text { extended Theory of Planned Behavior, Ramus \& } \\
\text { Killmer's model, Jones' model }\end{array}$ \\
\hline Attitudes & $\begin{array}{l}\text { Theory of Planned Behavior, Theory of Interpersonal } \\
\text { Behavior, Comprehensive Action Determination Model, } \\
\text { Voluntary Pro-environmental Behavior of Employees, } \\
\text { extended Theory of Planned Behavior, Tudor's } \\
\text { Conceptual Framework, Young's Process Framework, } \\
\text { Jones' model }\end{array}$ \\
\hline Social norms (Subjective/perceived norms) & $\begin{array}{l}\text { Theory of Planned Behavior, extended Theory of } \\
\text { Planned Behavior, Comprehensive Action Determination } \\
\text { Model, Voluntary Pro-environmental Behavior of } \\
\text { Employees, Theory of Interpersonal Behavior, extended } \\
\text { Theory of Planned Behavior, Ramus and Killmer's } \\
\text { model, Jones's model }\end{array}$ \\
\hline Injunctive norms & $\begin{array}{l}\text { Focus Theory of Normative Conduct, extended Theory } \\
\text { of Planned Behavior }\end{array}$ \\
\hline Descriptive norms & $\begin{array}{l}\text { Focus Theory of Normative Conduct, extended Theory } \\
\text { of Planned Behavior }\end{array}$ \\
\hline Awareness/knowledge & $\begin{array}{l}\text { Environmental Education, Action Competence } \\
\text { Approach, Tudor's Conceptual Framework, Young's } \\
\text { Process Framework }\end{array}$ \\
\hline Habit & $\begin{array}{l}\text { Theory of Interpersonal Behavior, Comprehensive } \\
\text { Action Determination Model, Voluntary } \\
\text { Pro-environmental Behavior of Employees, } \\
\text { extended Theory of Planned Behavior }\end{array}$ \\
\hline Affect & Theory of Interpersonal Behavior \\
\hline Gender & Psychosocial Demographics \\
\hline Age & $\begin{array}{l}\text { Psychosocial Demographics, Tudor's } \\
\text { Conceptual Framework }\end{array}$ \\
\hline Income & Psychosocial Demographics \\
\hline Household size & Psychosocial Demographics \\
\hline Residence & Psychosocial Demographics \\
\hline Marital status & Psychosocial Demographics \\
\hline Social class & Psychosocial Demographics \\
\hline Educational level & Psychosocial Demographics \\
\hline
\end{tabular}


Table 2. Cont.

\begin{tabular}{|c|c|}
\hline 1st Stage: & Source: \\
\hline Management support/superiors & $\begin{array}{l}\text { Tudor's Conceptual Framework, Young's Process } \\
\text { Framework, Ramus and Killmer's model, Temminck and } \\
\text { colleagues' model, Voluntary Pro-environmental } \\
\text { Behavior of Employees, Daily and colleagues' model }\end{array}$ \\
\hline Group dynamics & $\begin{array}{l}\text { Tudor's Conceptual Framework, Structuration Theory, } \\
\text { Voluntary Pro-environmental Behavior of Employees }\end{array}$ \\
\hline Social identity & Social Identity Theory, Theory of Interpersonal Behavior \\
\hline Organizational context & $\begin{array}{l}\text { Voluntary Pro-environmental Behavior of Employees, } \\
\text { extended Theory of Planned Behavior, Young's Process } \\
\text { Framework, Ramus and Killmer's model, } \\
\text { Lo's extended Theory of Planned Behavior }\end{array}$ \\
\hline Organizational structure & Tudor's Conceptual Framework \\
\hline Environmental Management Systems & Voluntary Pro-environmental Behavior of Employees \\
\hline Focus and Policies & $\begin{array}{l}\text { Tudor's Conceptual Framework, Voluntary } \\
\text { Pro-environmental Behavior of Employees }\end{array}$ \\
\hline Site/department type and size & Tudor's Conceptual Framework \\
\hline Organizational culture & Tudor's Conceptual Framework \\
\hline Organizational commitment & $\begin{array}{l}\text { Temminck and colleagues' model, Daily and } \\
\text { colleagues' model }\end{array}$ \\
\hline Situational factors/facilitating conditions & $\begin{array}{l}\text { Theory of Interpersonal Behavior, Competence Action } \\
\text { Determination Model, Young's Process Framework }\end{array}$ \\
\hline Perceived behavioral control/self-efficacy/coping & $\begin{array}{l}\text { Cognitive Theory of Stress, Theory of Planned Behavior, } \\
\text { Comprehensive Action Determination Model, Voluntary } \\
\text { Pro-environmental Behavior of Employees, extended } \\
\text { Theory of Planned Behavior, Protection Motivation } \\
\text { Theory, Ramus and Killmer's model, Jones' model }\end{array}$ \\
\hline Motivation (rewards) & $\begin{array}{l}\text { Tudor's Conceptual Model, Voluntary } \\
\text { Pro-environmental Behavior of Employees, } \\
\text { Young's Process Framework, Ramus and Killmer's } \\
\text { model }\end{array}$ \\
\hline $\begin{array}{l}\text { Intrinsic motivation (competence, relatedness } \\
\& \text { autonomy) }\end{array}$ & Self-Determination Theory \\
\hline Work satisfaction & Tudor's model, Young's model \\
\hline
\end{tabular}

\subsection{2nd Stage}

The second stage began with the exercise of grouping the literature by the variables examined into different excel sheets. The process was one of constant comparison, based on the level of their denoting data for differences and similarities, which resulted in the creation of categories. After one or several categories had been generated, the remaining variables were compared with other, which helped the researcher to create a new, modify the existing or combine the existing categories.

The remaining categories represent the most significant ones, which emerged from the literature analysis as Table 3 shows: 
Table 3. Variables identified after 2nd stage.

\begin{tabular}{|c|c|}
\hline 1st Stage & 2nd Stage \\
\hline $\begin{array}{l}\text { Environmental concern (defined as altruistic, biopsheric } \\
\text { values and awareness of consequences/needs/threat) } \\
\text { Ascription of responsibility } \\
\text { Personal Norms (defined as AC/NEP + AR) }\end{array}$ & Values \\
\hline $\begin{array}{l}\text { Intention } \\
\text { Attitudes } \\
\text { Awareness }\end{array}$ & Attitudinal processes \\
\hline $\begin{array}{l}\text { Social norms (Subjective/perceived norms) } \\
\text { Injunctive norms } \\
\text { Descriptive norms }\end{array}$ & Social factors \\
\hline $\begin{array}{l}\text { Habit } \\
\text { Affect }\end{array}$ & Non-rational factors \\
\hline $\begin{array}{l}\text { Gender } \\
\text { Age } \\
\text { Income } \\
\text { Household size } \\
\text { Residence } \\
\text { Marital status } \\
\text { Social class } \\
\text { Educational level }\end{array}$ & Demographic variables \\
\hline $\begin{array}{l}\text { Management support/superiors } \\
\text { Group dynamics } \\
\text { Social identity }\end{array}$ & Group factors \\
\hline $\begin{array}{l}\text { Organizational context } \\
\text { Organizational structure } \\
\text { Environmental Management Systems } \\
\text { Focus and Policies } \\
\text { Site/department type and size } \\
\text { Organizational culture } \\
\text { Organizational commitment } \\
\end{array}$ & Organizational factors \\
\hline Situational factors/facilitating conditions & Situational influences, constraints \\
\hline $\begin{array}{l}\text { Perceived behavioral control/self-efficacy/coping } \\
\text { Intrinsic motivation (competence, relatedness \& autonomy) }\end{array}$ & Internal Drivers \\
\hline $\begin{array}{l}\text { Extrinsic motivation (rewards) } \\
\text { Work satisfaction }\end{array}$ & External Drivers \\
\hline
\end{tabular}

\subsection{3rd Stage}

Once the data was reduced, it was integrated into a theoretical level. The third stage was begun by writing theoretical memos on each category and the relationship between these, which resulted in 4 different categories: Interpersonal factors, Motivational factors, Social factors and External factors as the Table 4 below shows: 
Table 4. Variables identified after 3rd Stage.

\begin{tabular}{|c|c|c|}
\hline 1st Stage & 2nd Stage & 3rd Stage \\
\hline $\begin{array}{l}\text { Environmental concern (defined as altruistic, biopsheric } \\
\text { values and awareness of consequences/needs/threat) } \\
\text { Ascription of responsibility } \\
\text { Personal Norms (defined as AC/NEP + AR) }\end{array}$ & Values & \multirow{4}{*}{$\begin{array}{l}\text { Intrapersonal } \\
\text { factors }\end{array}$} \\
\hline $\begin{array}{l}\text { Intention } \\
\text { Attitudes } \\
\text { Awareness }\end{array}$ & Attitudinal processes & \\
\hline $\begin{array}{l}\text { Habit } \\
\text { Affect }\end{array}$ & Non-rational factors & \\
\hline $\begin{array}{l}\text { Gender } \\
\text { Age } \\
\text { Income } \\
\text { Household size } \\
\text { Residence } \\
\text { Marital status } \\
\text { Social class } \\
\text { Educational level } \\
\end{array}$ & Demographic variables & \\
\hline $\begin{array}{l}\text { Social norms (Subjective/perceived norms) } \\
\text { Injunctive norms } \\
\text { Descriptive norms }\end{array}$ & Social factors & \multirow{2}{*}{$\begin{array}{l}\text { Interpersonal } \\
\text { factors }\end{array}$} \\
\hline $\begin{array}{l}\text { Management support/superiors } \\
\text { Group dynamics } \\
\text { Social identity }\end{array}$ & Group factors & \\
\hline $\begin{array}{l}\text { Organizational context } \\
\text { Organizational structure } \\
\text { Environmental Management Systems } \\
\text { Focus and Policies } \\
\text { Site/department type and size } \\
\text { Organizational culture } \\
\text { Organizational commitment } \\
\end{array}$ & Organizational factors & \multirow[t]{2}{*}{$\begin{array}{l}\text { External } \\
\text { factors }\end{array}$} \\
\hline Situational factors/facilitating conditions & Situational influences, constraints & \\
\hline $\begin{array}{l}\text { Perceived behavioral control/self-efficacy/coping } \\
\text { Intrinsic motivation (competence, relatedness \& autonomy) }\end{array}$ & Internal Drivers & \multirow{2}{*}{$\begin{array}{l}\text { Motivational } \\
\text { factors }\end{array}$} \\
\hline $\begin{array}{l}\text { Extrinsic motivation (rewards) } \\
\text { Work satisfaction }\end{array}$ & External Drivers & \\
\hline
\end{tabular}

\section{Results and Discussions}

\subsection{Results}

Looking at Table 4, the analysis demonstrates that there are four areas that influence pro-environmental behavior in the workplace: Intrapersonal, Motivational, Interpersonal and External factors. This is in line with the categorization made in current workplace literature such as Young's 
Lo's and Tudor's work on workplace behavior. It acknowledges the dichotomy of individual and organizational factors as well as considering group factors [6,7,72-74]. However, the analysis differs from the previous categorizations as "motivational factors" is now a distinct category whilst they were previously included in one of the other three categories. The separation is the result of the addition of intrinsic motivation, as now motivational factors refers to internal as well as external drivers and therefore does not fit into any of the other categories.

The category "intrapersonal factors" includes the groups: values, attitudinal processes, non-rational factors and demographics variables. The value group includes three variables environmental concern, ascription of responsibility and personal norms. Environmental concern originates from the general moral pro-environmental theories and their extended workplace models such as Scherbaum, and Temminck and their colleagues'. However, the review of the literature during the data gathering stage revealed that altruistic and biospheric values from the Value-Belief-Norm Theory as well as awareness of consequences are indistinguishable from NEP [87,88]. Furthermore, protection motivation research showed that the variable threat is the same as awareness of consequences $[22,89]$. Therefore, the meaning of environmental concern in this analysis is the result of the accumulation of the various bodies of literature on general and workplace pro-environmental behavior. The variable ascription of responsibility originates from the moral theories NAT and VBN, which were integrated into CADM and applied to the workplace in the VPBE model. Personal norms were multiply defined in the different bodies of literature as already discussed. The definition that derived from the analysis is based on the original definition in the Value-Belief-Norm Theory: The combination of awareness of consequences, environmental concern and ascription of responsibility, though it acknowledges that awareness of consequences and environmental concerns are the same measures. Intention and attitudes were included in the model through the rational category called attitudinal processes. As the previous chapter shows, a range of general and workplace theories included these variables in their models. The variable awareness, which originated from the environmental education literature but was also mentioned in Tudor's and Young's workplace models, was also added to the intrapersonal category due to its mediating effect on attitude highlighted by Tudor, Young and their colleagues work [6,7]. The group "Non-rational factors" was also included in the intrapersonal category and comprises of affect and habit. The variable affect is exclusively mentioned by Triandis in his Theory of Interpersonal Behavior but the variable habit was mentioned in various general and workplace theories including TIP, CADM, the VPBE and the extended TPB by Lo.

Two groups (Social and group factors) were identified within the Interpersonal factors category. The variables within the group "Social factors" mainly originate from the general behavioral models whilst the variables within the group "Group factors" mainly originate from the workplace behavioral models. The social factors group encompasses three variables: social norms, injunctive norms and descriptive norms. As with personal norms the data analysis showed that a variety of different norms were mentioned in the literature including subjective norms, perceived norms and social norms and in many cases the definitions were contradictory. Particularly, the distinction between the subjective and social dimension of norms created some difficulty for the synthesis of the variables. During the process it became clear that the three variables measures were similar enough to be categorized as one. The code social norm stood out as the strongest variable though the definition in Table 4 still acknowledges the subjective dimension. Injunctive and descriptive norms were added based on findings of the Focus 
Theory of Normative Conduct and the extended Theory of Planned Behavior by Lo and her colleagues. The second group, "Group factors" include the determinants originating from the workplace models such as Tudor's, Young's and their colleagues, Ramus and Killmer's, etc., VPBE and others as the previous chapter shows. Management support and group dynamics are two variables in this group. Management support is a very organizational specific variable and originated from workplace models such as Tudors' model, Young's Process Framework or Ramus and Killmer's model. Group dynamics is linked to the general behavioral theory "Structuration Theory" explaining the interaction between the agent and its environment but is also mentioned in workplace models such as VPBE and Tudor's model. Social identity, originating form general models such as Social Identity Theory and TIP is also included in this group because of its specific application to in and out groups in the workplace environment. The third category, "External factors" includes two distinct variables: organizational and facilitating conditions. The group Organizational factors include the variables context, culture, structure, Environmental Management Systems, Environmental policies, Department size and organizational commitment as discussed in the workplace models. The variable facilitating conditions originates from the general literature and refers more specifically to ease of behavior and other more practical barriers.

The last category "Motivational factors" includes the variables intrinsic motivation, extrinsic motivation, work satisfaction and perceived behavioral control. The variable perceived behavioral control, originates from a range of different sources as Table 2 shows. Specifically the protection motivation theories include this variable in their model as part of the coping mechanism to perceived stresses [22,89]. Though it is often seen to be an intrapersonal variable, the analysis of the sources showed that it was an important variable for motivation and was therefore added to this group. The distinction between intrinsic and extrinsic motivation is specific for this theory and warranted the addition of the motivational factors category. Coming from different research fields, intrinsic motivation originated from Ryan, Deci and their colleagues work, whilst extrinsic motivation was derived from general literature on incentives and the workplace models of Tudor, Young and VPBE. Lastly, work satisfaction was added as a motivational variable originating from Tudor and Young's work.

\subsection{Conceptualizing the Integrated Framework}

Based on these findings, a conceptual framework of the antecedents explaining pro-environmental behavior was formulated. Figure 1 takes into account the variables found in the grounded analysis and applied the learnings from the literature to interrelate them. Figure 1 is not intended to be rigid structure but is rather meant to provide a guide for discussion and further research.

The category external factors, which encompasses facilitating conditions and organizational factors as previously discussed are directly linked to employee behavior as the TIP and CADM models have demonstrated. The variables further influence extrinsic motivation and perceived behavioral control as the VPBE model showed. The interpersonal factors, shown in the right hand corner in Figure 1, are all directly linked to intention except for social norms. Social norms is linked to personal norms, which is then linked to intention. This relationship is based on the findings from the CADM, VPBE models and Structuration theory that show that the social and individual domains influence norms respectively. It also highlights the relationship between the social and subjective dimensions of norms as well as the 
interaction between values and norms. Descriptive and injunctive norms in return influence social norms as highlighted by the extended TPB by Lo and FTNC. The variable social identity is directly linked behavior based on the findings of TIP. The variables group dynamics and management support originate from the workplace literature and are here directly linked to intention. This relationship differs to the one suggested in Tudor's model where both were mediating variables to organizational constructs. The relationship was adapted based on Young and his colleagues' model to emphasize the importance of this category. The motivational variables are all directly linked to intention though two of them are influenced by external factors as well as perceived behavioral control. The relationship between perceived behavioral control and motivation is well established in motivational research literature and was therefore included in the model.

Figure 1. Conceptualizing the integrated framework.

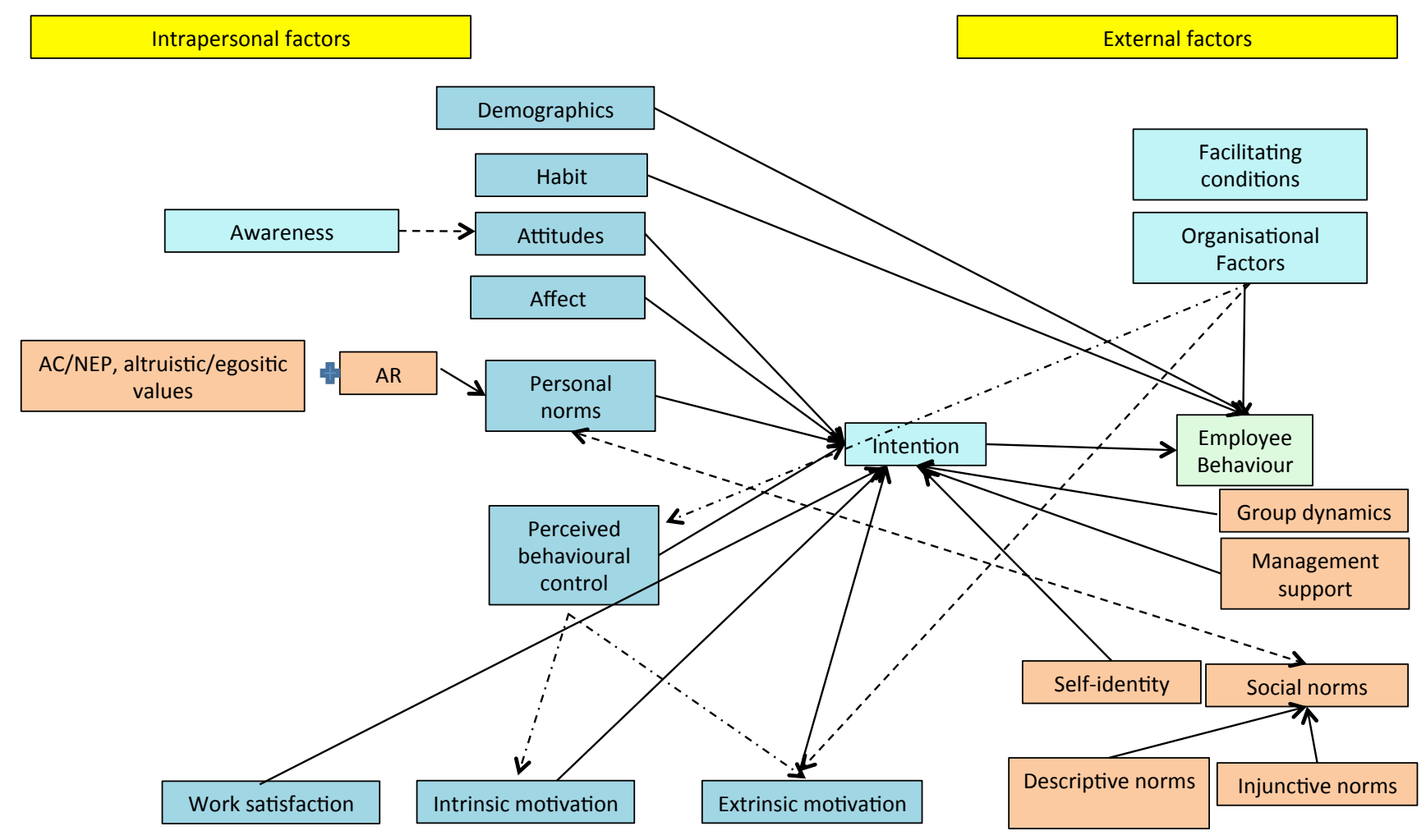

The intrapersonal dimension shown in Figure 1 shows a relationship between environmental concern, ascription of responsibility and personal norms as demonstrated in theories such as VBN, NAT, Lo and VPBE. This is also consistent with the learnings form the PMT and CTS theories. The variable affect is directly linked to intention as highlighted by TIP and attitudes shows a direct relationship as demonstrated in general models TPB and TIP, Lo's extended TPB and VPBE. The link between awareness and attitude originates from Tudor's work which was supported by Young's research. Lastly, habit and demographics are claimed to directly influence behavior by Triandis and 
psychosocial demographic literature. This linkage differs to Tudor work, where age was linked to organizational factors. The variable habit is directly linked to behavior as intention is a conscious process but habit an unconscious one, consistent with the findings of TIP and CADM.

\subsection{Implications for HR Practice}

Understanding the antecedents of pro-environmental behavior in the workplace can help create more specific interventions and human resource management strategies [90]. For example, when behavior is strongly related to attitudes, one can try to promote attitude changes towards particular proenvironmental behaviors, such as recycling, energy saving or travel behaviors, through awareness campaigns and other communicative strategies. Similar to attitudes, norms can be influenced through mere activation, information and training. When contextual factors inhibit particular behaviors, one can try to remove those barriers [90]. Habitual behavior is better addressed through strategies such as implementation intention, a strategy that regularly reminds employees to reflect consciously on their behavior that they generally do automatically, for example switching off computers and lights by offering primes and cues could be helpful if this is identified as the issue.

The previous as well as the proposed workplace models however offer further advice for interventions as they also emphasize organizational variables, specifically, the addition of management support and group dynamics. Energy champions, and teams, competitions and workshops can all be useful initiatives. Including these variables in a workplace framework adds another dimension as to what HR managers can do in order to create more sustainable behavior. Motivation has been mentioned by other workplace models but did not specify the type of motivation. Here is where the proposed model differs. Furthermore, the emphasis of motivational factors including (intrinsic as well as extrinsic) emphasizes the need to find the correct balance of rewards for employees. These factors can have a bigger impact on HR policies than previous general pro-environmental behavior theories that focus on mainly internal factors such as values and attitudes. Low intrinsic motivation can be addressed through the creation of autonomous motivation by: Asking open questions including inviting participation in solving important problems, active listening including acknowledging the employees' perspective, offering choices within structure, including the clarification of responsibilities, providing sincere, positive feedback that acknowledges initiative, and factual, non-judgmental feedback about problem, and develop talent and share knowledge to enhance competence and autonomy [35,91]. Alternatively, rewards can be offered if strategies based on extrinsic motivation are chosen. Another dimension that was not included in the other workplace models is affect. The most common strategy mentioned to change affect is that of emotive messaging and emotional appeals [92,93].

Overall, the proposed model can provide insights into possible interventions for pro-environmental behavior in the workplace. By referring to the organizational context, as well as management and group dynamic dimensions it extends from the recommendations that can be made by general pro-environmental models. Furthermore, it brings theory and practice closer together as factors such as group dynamics, management support and motivational factors can help create the right incentives to promote environmentally sustainable behavior. 


\subsection{Study Limitations and Future Research}

Any theory building approach has its limitations. All observations are made from a particular perspective, that is, they are standpoint-specific. Whatever emerges from a field through observation depends on the observer's position within it. In the same way, whatever emerges from the analysis of a set of data is necessarily guided by the questions asked and constructed by the researcher. However, the documentation of each phase of the research process limits the subjectivity and offers a systematic approach to theory building. The different approach to create a workplace pro-environmental model has also shown advantages over the standard extension of theories. Through the comparison of the theories on a like for like basis variables such as affect or intrinsic motivation emerged. It also established common findings across various theories and fields of research that should be acknowledged in future research such as the link between attitudes, intention and behavior, the consideration of a moral and non-rational dimension to human behavior and the addition of organizational context to workplace models. The data analysis also highlighted how variables have been differently defined, such as personal norms and beliefs. More consistent definitions could help further research to be more consistent and to avoid confusion. Particularly, the relationship between social norms and personal norms and the social/subjective component of norms require further investigation. The model also identified further relationships between variables that could be explored further, such as the direct link between interpersonal and motivational variables and intention as well the link between awareness and attitudes.

Quantitative studies will be carried out in the next phase of this research to confirm the relationship between the different variables and to confirm validity and reliability of the overall framework but additional empirical research is warranted to provide clarity on the impact of these factors. Future research could include case studies to confirm if HR practices targeting these variables have the desired effect.

\section{Conclusions}

The major contribution of this review was to synthesize the leading models and theories explaining general and pro-environmental behavior and through this process, propose an integrated framework for environmentally friendly behavior in the workplace. The framework highlights common findings as well as new insights that emerged from the analysis of the reviewed literature. Common findings include the important distinction between organizational and individual antecedents, the categorization of variables into intra, inter and social factors as well as the establishment of common variables such as attitudes, intention and personal norms. Differences that were highlighted include the new category motivational factors as well as new variables such as affect and intrinsic motivation. This proposed framework further highlights the differences to general pro-environmental models by including the variables group dynamics, management support and work satisfaction. Particularly, these variables can help evaluate the success of existing interventions that already target these areas as well as help understand what type of future interventions could be designed. Lastly, this paper shows that synthesizing the current literature from different fields of research is a useful tool for theory generation and synthesis research. 


\section{Acknowledgments}

The author is grateful to Cheryl Rodgers and Michael Wood for their helpful and encouraging comments.

\section{Conflicts of Interest}

The author declares no conflict of interest.

\section{References}

1. IPCC. Summary for Policymakers. In Climate Change 2013: The Physical Science Basis. Contribution of Working Group I to the Fifth Assessment Report of the Intergovernmental Panel on Climate Change; Stocker, T.F., Qin, D., Plattner, G.K., Tignor, M., Allen, S.K., Boschung, J., Nauels, A., Xia, Y., Bex, V., Midgley, P.M., Eds.; Cambridge University Press: Cambridge, UK; New York, NY, USA, 2013; pp. 3-29.

2. IPCC. Summary for Policymakers. In Climate Change 2007: The Physical Science Basis. Contribution of Working Group I to the Fourth Assessment Report of the Intergovernmental Panel on Climate Change; Solomon, S., Qin, D., Manning, M., Chen, Z., Marquis, M., Averyt, K.B., Tignor, M., Miller, H.L., Eds.; Cambridge University Press: Cambridge, UK; New York, NY, USA, 2007; pp. 1-17.

3. Houghton, J.T. Climate Change 1995: The Science of Climate Change: Contribution of Working Group I to the Second Assessment Report of the Intergovernmental Panel on Climate Chang, 2nd ed.; Cambridge University Press: Cambridge, UK, 1996.

4. Agyeman, J.; Kollmus, A. Mind the Gap: Why do people act environmentally and what are the barriers to pro-environmental behavior? Environ. Educ. Res. 2002, 8, 239-260.

5. Lülfs, R.; Hahn, R. Corporate Greening beyond Formal Programs, Initiatives, and Systems: A Conceptual Model for Voluntary Pro-environmental Behavior of Employees. Eur. Manag. Rev. 2013, 10, 83-98.

6. Young, W.; Davis, M.; McNeill, I.M.; Malhorta, B.; Russell, S.; Unsworth, K.; Clegg, C.W. Changing Behavior: Successful Environmental Programmes in the Workplace. Bus. Strategy Environ. 2013, doi:10.1002/bse.1836.

7. Tudor, T.L.; Barr, S.W.; Gilg, A.W. A Novel Conceptual Framework for Examining Environmental Behaviour in Large Organizations: A Case Study of the Cornwall National Health Service (NHS) in the United Kingdom. Environ. Behav. 2008, 40, 426-450.

8. Jackson, T. Motivating Sustainable Consumption. A Review of Evidence on Consumer Behaviour and Behavioral Change. A Report to the Sustainable Development Research Network; University of Surrey: Brighton, UK, 2005.

9. Turuga, R.M.; Howarth, R.B.; Borsuk, M.E. Pro-environmental behaviour Rational choice meets moral motivation. Ann. NY Acad. Sci. 2010, 1185, 211-224.

10. De Groot, J.I.; Steg, L. Relationships between value orientations, self-determined motivational types and pro-environmental behavioural intentions. J. Environ. Psychol. 2010, 30, 368-378. 
11. Binney, W.; Hall, M. Towards an understanding of residents' pro-environmental behavior. In Procedings of the ANZMAC 2011 Conference: Marketing in the Age of Consumerism: Jekyll or Hyde? Perth, WA, Australia, 28-30 November 2011; pp. 1-7.

12. De Groot, J.I.M.; Steg, L. Mean or green: Which values can promote stable pro-environmental behavior? Conserv. Lett. 2009, 2, 61-66.

13. Hansla, A. Value Orientation, Awareness of Consequences, and Environmental Concern; Department of Psychology, University Gothenburg: Gothenburg, Sweden, 2011.

14. Poortinga, W.; Spence, A.; Demski, C.; Pidgeon, N.F. Individual-motivational factors in the acceptability of demand-side and supply-side measures to reduce carbon emissions. Energ. Pol. 2012, 48, 812-819.

15. Steg, L.; de Groot, J.I.; Dreijerink, L.; Abrahamse, W.; Siero, F. General antecedents of personal norms, policy acceptability, and intentions: The role of values, worldviews, and environmental concern. Soc. Nat. Resour. 2011, 24, 349-367.

16. Dunlap, R.E. The New Environmental Paradigm Scale: From Marginality to Worldwide Use. J. Environ. Educ. 2008, 40, 3-18.

17. Amburgey, J.W.; Thoman, D.B. Dimensionality of the New Ecological Paradigm Issues of Factor Structure and Measurement. Environ. Behav. 2012, 44, 235-256.

18. Schwartz, S.H. Are there universal aspects in the structure and contents of human values? J. Soc. Issues 1994, 50, 19-45.

19. Clayton, S.; Myers, G. Conservation Psychology: Understanding and Promoting Human Care for Nature; John Wiley \& Sons: New York, NY, USA, 2011.

20. Schwartz, S.H.; Cieciuch, J.; Vecchione, M.; Davidov, E.; Fischer, R.; Beierlein, C.; Ramos, A.; Verkasalo, M.; Lönnqvist, J.-E.; Demirutku, K. Refining the theory of basic individual values. J. Personal. Soc. Psychol. 2012, 103, 663-688.

21. Stern, P.C. New Environmental Theories: Toward a Coherent Theory of Environmentally Significant Behavior. J. Soc. Issues 2000, 56, 407-424.

22. Stern, P.C.; Dietz, T.; Abel, T.; Guagnano, G.A.; Kalof, L. A value-belief-norm theory of support for social movements: The case of environmentalism. Res. Hum. Ecol. 1999, 6, 81-97.

23. Ajzen, I. The theory of planned behavior. Organ. Behav. Hum. Decis. Process. 1991, 50, 179-211.

24. Ajzen, I.; Fishbein, M. The influence of attitudes on behavior. In The Handbook of Attitudes; Albarracin, B.T., Johnson, B.T., Zanna, M.P., Eds.; Erlbaum: Mahwah, NJ, USA, 2005; pp. 173-221.

25. Gagnon, M.-P.; Godin, G.; Gagné, C.; Fortin, J.-P.; Lamothe, L.; Reinharz, D.; Cloutier, A. An adaptation of the theory of interpersonal behaviour to the study of telemedicine adoption by physicians. Int. J. Med. Inform. 2003, 71, 103-115.

26. Triandis, H.C. Values, attitudes, and interpersonal behavior. In Nebraska Symposium on Motivation; Howe, H., Page, M., Eds.; University of Nebraska Press: Lincoln, NE, USA, 1979; pp. 195-295.

27. Lülfs, R.; Hahn, R. Sustainable Behaviour in the Business Sphere-A Comprehensive Overview of the Explanatory Power of Psychological Models. Organ. Environ. 2014, 27, 43-64.

28. Sopha, B.M. Sustainable Paper Consumption: Exploring Behavioral Factors. Soc. Sci. 2013, 2, 270-283.

29. Rogers, R.W. A protection motivation theory of fear appeals and attitude change. J. Psychol. 1975, 91, 93-114. 
30. Rogers, R.W.; Prentice-Dunn, S. Protection motivation theory. In Handbook of Health Behavior Research: Vol 1. Determinants of Health Behavior: Personal and Social; Gochmann, D., Ed.; Plenum: New York, NY, USA, 1997; pp. 96-98.

31. Floyd, D.L. A meta analysis of research on protection motivation theory. J. Appl. Soc. Psychol. 2000, 3, 407-429.

32. Homburg, A.; Stolberg, A. Explaining pro-environmental behavior with a cognitive theory of stress. J. Environ. Psychol. 2006, 26, 1-14.

33. Kim, S.; Jeong, S.-H.; Hwang, Y. Predictors of pro-environmental behaviors of American and Korean students the application of the theory of reasoned action and protection motivation theory. Sci. Commun. 2013, 35, 168-188.

34. Lazarus, R.S. Fifty Years of the Research and Theory of RS Lazarus: An Analysis of Historical and Perennial Issues; Psychology Press: Hove, UK, 2013.

35. Deci, E.L.; Ryan, R.M. Facilitating optimal motivation and psychological well-being across life's domains. Can. Psychol. 2008, 49, 14-23.

36. Ryan, R.M.; Weinstein, N.; Bernstein, J.; Brown, K.W.; Mistretta, L.; Gagné, M. Vitalizing effects of being outdoors and in nature. J. Environ. Psychol. 2010, 30, 159-168.

37. Pelletier, L.G.; Fortier, M.S.; Vallerand, R.J.; Briere, N.M. Associations among perceived autonomy support, forms of self-regulation, and persistence: A prospective study. Motiv. Emot. 2001, 25, 279-306.

38. Pelletier, L.G.; Tuson, K.M.; Green-Demers, I.; Noels, K.; Beaton, A.M. Why are you doing things for the environment? The motivation toward the environment scale. J. Appl. Soc. Psychol. 1998, 28, 437-468.

39. Osbaldiston, R.; Sheldon, K.M. Promoting internalized motivation for environmentally responsible behavior: A prospective study of environmental goals. J. Environ. Psychol. 2003, 23, 349-357.

40. Lepper, M.R.; Henderlong, J. Turning "play" into "work" and "work" into "play": 25 years of research on intrinsic versus extrinsic motivation. In Intrinsic and Extrinsic Motivation: The Search for Optimal Motivation and Performance; Sansone, C., Harackiewicz, J.M., Eds.; Academic Press: San Diego, CA, USA, 2000; pp. 257-307.

41. Bedford, T.; Collingwood, P.; Darnton, A.; Evans, D.; Gatersleben, B.; Abrahamse, W.; Jackson, T. Motivations for Pro-Environmental Behaviour: A Report to the Depart for Environment, Food and Rural Affairs; DEFRA: London, UK, 2008.

42. Kassirer, J. Tools of Change Workbook. Available online: http://www.toolsofchange.com/en/toolsof-change/ (accessed on 19 April 2014).

43. McKenzie-Mohr, D. Fostering Sustainable Behaviour. Available online: http://www.cbsm.com/ public/world.lasso (accessed on 19 January 2014).

44. McKenzie-Mohr, D. Tools of Change. Available online: http://www.toolsofchange.com/en/ programs/community-based-social-marketing/ (accessed on 19 Janaury 2014).

45. Hidi, S.; Harackiewicz, J.M. Motivating the academically unmotivated: A critical issue for the 21st century. Rev. Educ. Res. 2000, 70, 151-179.

46. Palmer, J. Environmental Education in the 21st Century: Theory, Practice, Progress and Promise; Routledge: New York, NY, USA, 2002. 
47. Huckle, J. Environmental education and sustainability: A view from critical theory. In Environmental Education: A pathway to sustainability; John Fien, Ed.; Deakin University Press: Melbourne, Australia, 1993; pp. 43-68.

48. Bratt, C. The Impact of Norms and Assumed Consequences on Recycling Behavior. Environ. Behav. 1999, 31, 630-656.

49. Jensen, B.B.; Schnack, K. The action competence approach in environmental education: Reprinted from Environmental Education Research (1997). Environ. Educ. Res. 2006, 12, 471-486.

50. Hobson, K. Sustainable Lifestyles: Rethinking Barriers and Behaviour Change. In Exploring Sustainable Consumption: Evironmental Policy and the Social Sciences; Murphy, J., Cohen, M.J., Eds.; Pergamon Press: Oxfrod, UK, 2001; pp. 191-209.

51. Blumstein, D.T.; Saylan, C. The Failure of Enviornmental Education (and How We Can Fix It). PLoS Biol. 2007, doi:10.1371/journal.pbio.0050120. Available online: http:/www.plosbiology.org/ article/info\%3Adoi\%2F10.1371\%2Fjournal.pbio.0050120 (accessed on 15 June 2014).

52. Whitmarsh, L.; O’Neill, S. Green identity, green living? The role of pro-environmental self-identity in determining consistency across diverse pro-environmental behaviours. J. Environ. Psychol. 2010, 30, 305-314.

53. Barr, S. Strategies for sustainability: Citizens and responsible environmental behaviour. Area 2003, 35, 227-240.

54. Jensen, B.B. Knowledge, Action and Pro-environmental Behaviour. Environ. Educ. Res. 2002, 8, 325-334.

55. Breiting, S.; Mogensen, F. Action competence and environmental education. Camb. J. Educ. 1999, 29, 349-353.

56. Mogensen, F.; Schnack, K. The action competence approach and the "new" discourses of education for sustainable development, competence and quality criteria. Enviro. Educ. Res. 2010, $16,59-74$.

57. Schultz, P.; Zelezny, L.C. Values and proenvironmental behavior. J. Cross-Cult. Psychol. 1998, 29, 540-558.

58. Gatersleben, B.; Steg, L.; Vlek, C. Measurement and Determinants of Environmentally Significant Consumer Behaviour. Environ. Behav. 2002, 34, 335-362.

59. Bamberg, S.; Möser, G. Twenty years after Hines, Hungerford, and Tomera: A new meta-analysis of psycho-social determinants of pro-environmental behaviour. J. Environ. Psychol. 2007, 27, $14-25$.

60. Giddens, A. The Constitution of Society: Outline of the Theory of Structuration; Polity Press: Oxford, UK, 1984.

61. Giddens, A. The Constitution of Society: Outline of the Theory of Structuration; John Wiley \& Sons: New York, NY, USA, 2013.

62. Boucaut, R. Understanding workplace bullying: A practical application of Giddens' structuration theory. Int. Educ. J. 2001, 2, 65-73.

63. Hobson, K. Thinking habits into action: The role of knowledge and process in questioning household consumption practices. Local Environ. 2003, 8, 95-112. 
64. Hargreaves, T. Making Pro-Environmental Behaviour Work: An Ethnographic Case Study of Practice, Process and Power in the Workplace. Unpublished Ph.D. Thesis, University of East Anglia, Norwich, UK, 2008.

65. Cialdini, R.B. Crafting Normative Messages to Protect the Environment. Curr. Dir. Psychol. Sci. 2003, 12, 105-109.

66. Kallgren, C.A.; Reno, R.R.; Cialdini, R.B. A Focus Theory of Normative Conduct: When Norms Do and Do not Affect Behavior. Personal. Soc. Psychol. Bull. 2000, 26, 1002-1012.

67. Fornara, F.; Carrus, G.; Passafaro, P.; Bonnes, M. Distinguishing the sources of normative influence on proenvironmental behaviors: The role of local norms in household waste recycling. Group Processes Intergroup Relat. 2011, 14, 623-635.

68. Jenkins, R. Social Identity; Taylor \& Francis: London, UK, 2008.

69. Conner, M.; Armitage, C.J. Extending the Theory of Planned Behavior: A Review and Avenues for Further Research. J. Appl. Soc. Psychol. 1998, 28, 1429-1464.

70. Poortinga, W.; Whitmarsh, L.; Suffolk, C. The introduction of a single-use carrier bag charge in Wales: Attitude change and behavioural spillover effects. J. Environ. Psychol. 2013, 36, 240-247.

71. Lo, S.H.; Peters, G.J.Y.; van Breukelen, G.J.P.; Kok, G. Only reasoned action? An interorganizational study of energy-saving behaviors in office buildings. Energy Effic. 2014, 1-15, doi:10.1007/s12053-014-9254-X.

72. Lo, S.H.; Peters, G.J.Y.; van Breukelen, G.J.P.; Kok, G. A review of determinants of and interventions for proenvironmental behaviors in organizations. J. Appl. Soc. Psychol. 2012, 42, 2933-2967.

73. Lo, S.H.; van Breukelen, G.J.P.; Peters, G.J.Y.; Kok, G. Proenvironmental travel behavior among office workers: A qualitative study of individual and organizational determinants. Transp. Res. 2013, 56, 11-22.

74. Lo, S.H.; van Breukelen, G.J.P.; Peters, G.J.Y.; Kok, G. Energy-Related Behaviors in Office Buildings: A Qualitative Study on Individual and Organisational Determinants. Appl. Psychol. 2012, 61, 227-249.

75. Ramus, C.A.; Killmer, A.B.C. Corporate greening through prosocial extrarole behaviours-A conceptual framework for employee motivation. Bus. Strategy Environ. 2007, 16, 554-570.

76. Jones, R.E. Understanding paper recycling in an institutionally supportive setting: An application of the theory of reasoned action. J. Environm. Syst. 1989, 19, 307-321.

77. Scherbaum, C.A.; Popovich, P.M.; Finlinson, S. Exploring Individual-Level Factors Related to Employee Energy-Conservation Behaviors at Work. J. Appl. Soc. Psychol. 2008, 38, 818-835.

78. Daily, B.F.; Bishop, J.W.; Govindarajulu, N. A conceptual model for organizational citizenship behavior directed toward the environment. Bus. Soc. 2009, 48, 243-256.

79. Temminck, E.; Mearns, K.; Fruhen, L. Motivating Employees towards Sustainable Behaviour. Bus. Strategy Environ. 2013, doi:10.1002/bse.1827. Available online: http://onlinelibrary.wiley. com/doi/10.1002/bse.1827/abstract (accessed on 15 June 2014).

80. Bissing-Olson, M.J.; Iyer, A.; Fielding, K.S.; Zacher, H. Relationships between daily affect and pro-environmental behavior at work: The moderating role of pro-environmental attitude. J. Organ. Behav. 2012, 34, 156-175. 
81. Bendassolli, P.F. Theory Building in Qualitative Research: Reconsidering the Problem of Induction. Qual. Soc. Res. 2013, 14, 1-20.

82. Robson, C. Real World Research: A Resource for Users of Social Research Methods in Applied Settings, 3rd ed.; John Wiley \& Sons: Chichester, UK, 2011.

83. Osbaldiston, R.; Scott, J.P. Environmental sustainability and behavioral science meta-analysis of proenvironmental behavior experiments. Environ. Behav. 2012, 44, 257-299.

84. Guion, L.A.; Diehl, D.C.; McDonald, D. Triangulation: Establishing the Validity of Qualitative Studies. Available online: http://edis.ifas.ufl.edu/fy394 (accessed on 15 June 2014).

85. Young, W.; Middlemiss, L. A rethink of how policy and social science approach changing individuals' actions on greenhouse gas emissions. Energ. Pol. 2012, 41, 742-747.

86. Klöckner, C.A.; Blöbaum, A. A comprehensive action determination model: Toward a broader understanding of ecological behaviour using the example of travel mode choice. J. Environ. Psychol. 2010, 30, 574-586.

87. Wiidegren, Ö. The new environmental paradigm and personal norms. Environ. Behav. 1998, 30, $75-100$.

88. Stern, P.C.; Dietz, T.; Guagnano, G.A. The New Ecological Paradigm in Social Psychological Context. Environ. Behav. 1995, 27, 723-743.

89. Oreg, S.; Katz-Gerro, T. Predicting proenviornmental behavior cross-nationally values, the Theory of Planned Behavior, and the Value-Belief-Norm Theory. Environ. Behav. 2008, 38, 462483.

90. Steg, L.; Vlek, C. Encouraging pro-environmental behaviour: An integrative review and research agenda. J. Environ. Psychol. 2009, 29, 309-317.

91. Stone, D.N.; Deci, E.L.; Ryan, R.M. Beyond talk: Creating autonomous motivation through self-determination theory. J. Gen. Manag. 2010, 34, 75-91.

92. Dolan, P.; Hallsworth, M.; Halpern, D.; King, D.; Vlaev, I. MINDSPACE Influencing Behaviour through Public Policy; Institute for Government: London, UK, 2009.

93. Bulbul, C.; Menon, G. The Power of Emotional Appeals in Advertising. J. Advert. Res. 2010, 50, 169-180.

(C) 2014 by the author; licensee MDPI, Basel, Switzerland. This article is an open-access article distributed under the terms and conditions of the Creative Commons Attribution license (http://creativecommons.org/licenses/by/3.0/). 